\title{
Coal Mining under Water-containing condition and it's Research Status and Trend
}

\author{
SUN Xue-yang ${ }^{1, a}$, LIANG Qian-wen ${ }^{1, b}$, FU Heng-xin ${ }^{1, c}$, LIU Zi-qiang ${ }^{1, b}$ \\ ${ }^{1}$ Xi'an University of Science and Technology , School of Geology and Environment, Xi'an city, \\ 710054 , China \\ asxy163@163.com, ${ }^{\mathrm{b}}$ 862716575@qq.com, ${ }^{\mathrm{c}}$ 947145866@qq.com, ${ }^{\mathrm{d}} 310714552$ @qq.com
}

\begin{abstract}
Keywords: Coal mining under water-containing; Protection of the ecological environment; Development trend
\end{abstract}

Abstract. The one core content of Green mining technology is how to achieve coal mining under water-containing, which means implementing efficient exploitation of coal resources and protecting the valuable water resources in coal mining, and is the trends and requirements of the development in the coal mining area. Coal mining under water-containing is important, and we should determine the mining upper limit and choose the reasonably mining method according to the specific hydrogeological conditions. The achievement in coal mining technology with water protection is summarized systematically, and its present theories are overall summed up and evaluated by using the method of comprehensive analysis after reviewing the published literature in recent years. The research will provide a reference for further research in this filed.

\section{Introduction}

The mass exploitation of coal resources and unreasonable exploitation and utilization made the surrounding rock deformation and failure consequently causing some safety problem like land subsidence, collapse in mining area, mine inflow water, water inrush and sand inrush. Artificially drain away mining water and dewatering in mining fissure not only damage the water resources of underground and surface but also bring some inconvenience to the local production and life. This problem is particularly prominent in ecologically fragile zone. According to statistics, 71 percent of coal mining area have water shortage problem because of large-scale coal mining and 40 percent of coal mining area have serious water shortage among the eighty-six state owned key coal mining area nationwide.

In view of a series of accidents which emerged in coal mining and the severe fact that the ecologically vulnerable regions had been seriously damaged due to mining activity, the concept of coal mining under water-contained has been established and the research focuses on how to implement coal mining under water-contained. The key points of mining under water-contained condition are determining the upper limits of mining and the mining method. Some researcher in China study the damage of overlaying strata after coal mining with different methods from different aspects. The failure regularity and failure modes are summarized. Thus the height of breaking overlying strata has been accurately forecast to provide technical support for protecting the aquifer and restore local ecosystems by studying the aquifer reconstruction. There are also some scholars studying this problem from the mining methods. Taking different mining methods in different regions can effectively reduce the incident of water inrush, and control the extent of damage to the ecological environment .

This paper summarizes and analyzes coal mining under water-contained strata and coal mining methods, and discusses the questions in this field and the trend in this domain to provide consult to achieve mining under water-contained overlaying in the area with fragile ecological environment.

\section{The basic idea of mining under water-containing condition.}


Mining under water-containing condition is that mining activity use mining technology to present face inrush and consciously protect water resource at the same times. Water preserving mining was put forward for the water drained away in Salawusu and the ecological environment deterioration when mining coal in Jurassic coal field in north Shaanxi province. The basic idea of mining under water-containing condition was formed around after 1990. In 1992, Fan Li-min firstly put forward the idea of water preserving mining in the literature entitled Environmental Geology in Shenmu Mining Area. Fan thought that mass water and sand gushing in mine caused groundwater table to fall, surface water to dry, the geological environment to deteriorate, and sands to invade. Hence groundwater protection is so important in the area with fragile environment. Qian Gao-ming in 2003 put forward the green mining concept and technology system. The chief content of their philosophy is mining under water-containing condition. After 2004 years Wang Shuangming and Fan Li-min systematically study the philosophy of preserving water mining and present the principle, basic ideas and put forward the technology of water keeping mining being core with protection ecological water level. They have made a major breakthrough in the mining engineering practice in Yushuwan mine and local coal mine in Yuyang area .

\section{Ways to study the law of overburden failure}

In recent years, with the attention to environment issues, green mining became more and more important especially in ecologically fragile areas. To protect water resources and achieve safety production in coal mining, it is necessary to study the law of overburden failure in mining, and predict failure height. Coal mining should be guided to make preserving mining come true . Nowadays, the main study methods are as follows.

\section{The theoretical analysis and empirical formula calculation}

There is a general cognition on overburden moving law: there are three sections in horizon and three sections in vertical in the overlying rock failure at home and abroad. Meanwhile there are so many hypotheses on overlying rock structure, mainly including pressure arch hypothesis, cantilever hypothesis, hinged rock block hypothesis, and preformed fissure hypothesis.

Qian Minggao firstly proposed the concept of "coal green mining" and put forward the key strata theory of overlying rock breaking. Later Yang Bensheng got more concise expression according to the key strata theory and synchro-deformation of roof. Xu Jilin, Wang Xiaozhen, etc studied the overburden key strata and aquifer, and presented a sorting method of "two types and four kinds" for key strata to the shallow coal seam in Yulin mine area. This method can interpret occurrence mechanism of abnormal coal mine roof water inrush accident, and carry out a new way to predict the height of water flowing fractured zone through the location of key strata. It could distinguish the abnormal development of water flowing fractured zone height induced by the changed structure of overlaying key strata. According to key strata theory, Miao Xiexing raise the key aquifer theory. Hou Shijie proposed formula for judging overlying strata fall by full thick and add a judgment norm of key strata theory using in mining area with shallow coal seam. He deduced the calculation formula of elastic modulus, bearing load and limited span of combination key strata. Chen Kai used trend surface method to predict the height of water flowing fractured zone. Shi Qinglong researched the motion character of the overlying rock of depth face based on the theory that divide face roof into four parts, and deduced the theoretical calculation formula of water flowing fractured zone which considers these factors such as working thickness, mining depth, mining face span, the mechanical property rock, combination characteristics of rock layer and hydraulic pressure of aquifer.

Empirical formula using the equation for predicting the height of water flowing fractured zone comes from the regulation on coal mining and reserving coal pillar in the main coal roadway under Buildings, water, rail and the regulation on coal mine hydrologic geology. In recent year some researcher summarized the discipline in different area based on their owned experience. They infer the calculation method for the height of caving zone and the water flowing fractured zone in shallow coal ream and mining thick coal . 


\section{Field measurement analysis method}

Field measurement analysis method is mainly to analyze deformation and movement law of overburden and to summarize the calculation formula of failure height to guide the produce in the area with same condition. In-situ test method mainly includes the experiment method of injecting water into borehole, flushing fluid observation method, ultrasonic imaging method, sound wave CT tomography method, high-density resistivity method, and monitoring method using MS. LIU Chuan-wu confirmed the break height of coal seam floor after mining with the acoustic testing technique $^{[13]}$. Shandong university of science and technology invented a testing technique for failure height which measures leakage in two boreholes ${ }^{[14]}$. WANG Hua applied the electrical method in parallel network monitoring system based on the second level resistivity method to measure the height of water flowing zone. This method synchronize detects the development process of height of water-conducting fissure zone and gets the height in more accurate way ${ }^{[15]}$. WANG Qiqing Perform in-situ water pressure test before and after mining and simulation experience to test the changing permeability in the process of overlaying rock break indoor based on exploration test taking the representative mine in North of Shaanxi as example. The conditions of water preserving mining in ecological fragile district were divided into four kind and deduced the dividing area formula based on principle of water balance according to the diving leakage and the changed relation of diving level ${ }^{[16]}$.

\section{Method of similar material simulation}

MA Qingyun studied the overlying rock movement law and destruction by similar material simulation ${ }^{[17]}$. HUANG Qingxiang took Yushuwan mine as an example, carrying out solid-liquid coupling similar material simulation test in long wall face, and found that the key factor affecting the stability of water-resisting layer in mining are ascending crack and descending $\mathrm{crack}^{[18]}$. MA Liqiang get the overlying rock destruction and the height of water flowing fissure zone in shallow coal seam using similar material simulation. It has laid a foundation for the protection water mining in the shallow coal seam in the western mining area ${ }^{[19]}$. WANG Xiaozhen perform an similar material experiment of unconsolidated formation, deducing a technique to determine the load transmission coefficient of aquifer. In the meanwhile he presented the prediction technique of Water inrush danger zone mining coal under the confined aquifer in the unconsolidated formation, and guided the practice to prevent water inrush disaster mining coal under the confined aquifer in the unconsolidated formation in Qidong coal mine ${ }^{[20-21]}$. HUANG Qingcun stressed that the continuity of overlying disrupted strata decided the water-resisting property of overlying strata by the simulation study and measured mining damage in the north of Shaanxi province where mining shallow coal seam under water-containing strata. He presented the criterion of the watertightness of aquifuge with the ratio of aquifuge and mining coal thickness based on the relation between mining height and aquifuge thickness, and had the mining coal under water-containing into natural coal mining controllable coal mining and particular coal mining which provides scientific basis for mining the shallow buried coal seam under water-containing.

\section{Numerical simulation method}

Numerical simulation can realize dynamic observation process for collapse of mining coal overburden. Nowadays, discrete element method, finite difference method, boundary element method and finite element method are the frequently-used numerical simulation methods. Charliec use numerical simulation $\left(\mathrm{FLAC}^{2 \mathrm{D}}\right)$ to find out the range impacted by mining working face in Krist ineberg metal mine in Sweden ${ }^{[23]}$. FAN Juan took Yushuwan coal mine as an example, and used the result of numerical simulation $\left(\mathrm{FLAC}^{3 \mathrm{D}}\right.$ ), and presented the stress shell in overlying strata, indicating that the stress shell's losing of stability is the main reason for the fierce appearance of mine ground pressure $^{[24]}$. GUAN Kai used UDEC software to simulate working coal face in shallow coal ream, analyzed the coupling function between surface soil layer and key stratum in shallow buried coal, and deduced that the coupling effect of surface soil layer and key stratum must take into account when predict mining subsidence in the situation with thin surface soil layer or thick key strata ${ }^{[25]}$. ZHANG Rongliang applied ANSYS software which was powered by finite element method to study ground deformation caused by mining inclined coal seam, and worked out the general regularity and 
characteristics of ground deformation and movement ${ }^{[26]}$. WANG Shuang-ming analyzed space relation between coal strata and aquifer, divided the region with mining under water-containing layer, and Put forward the planning scheme on method of coal mining in different area ${ }^{[27-28]}$. ZHAO Deshen used the software powered by finite element method to conduct the 3-d numerical simulation on coal strata with soft rock layer, revealed overburden destruction law in the mining condition that top-coal caving in three soft coal seam under large-scale water mass, and confirmed the height of water flowing fissure zone ${ }^{[29]}$.

The aforementioned method have their own advantages and disadvantages in the process of studying mining under water-containing layer. Scholars home and abroad gradually combine, replenish, and perfect these methods including qualitative analysis. The numerical and physical simulation and the modern test methods make the analysis model predicting outcomes become more and more close to true situation.

\section{The current research status of mining method}

\section{The present main mining methods in China}

At present, The primary mining methods include longwall integrated mechanization full-seam mining coal method, limited height mining method, Layered intermittent mining method, Longwall roof-caving coal mining method using comprehensive mechanized equipment, the short wall comprehensive mechanized coal mining method, pillar mining coal method and filling working face after mining method in China. In these methods, the later six methods have fatal impact on coming true mining coal under water-containing layer.

(1) Longwall integrated mechanization full-seam mining coal method

Longwall integrated mechanization full-seam mining coal method is modern coal mining method using and developing in key state-owned coal mine. This method took safe and efficient model with high resistance, high-power, information controlling, super long coal face, and high speed at propulsion, making coal mine have a large production. When applying this method, people must ensure to form steady three zone and the aquifer in the curve subsidence zone which is in stabilization to implement mining under water-containing layer.

(2) The mining method limited height

The mining method limited height is to ensure safety mining coal under aquifer by using the limited mining height method and to ensure the height of water flowing fissure zone not to reach the critical height of aquifer because of the position of aquifer. The limited height mining method is taken when mining is done under water-containing layer and the thickness of overburden does not assure the water proof stability of aquifer in curve subsidence zone. This mining method can effectively preserve water but lead to a lower coal mining rate and resource utilization rate because of limiting mining height.

(3) Layered intermittent mining method

Layered intermittent mining method is that the mining of the top layer is done first during slice mining of an thick coal seam and then the next slice after the ground movement and deformation caused by the top layer mining is stabilized.

(4)Longwall roof-caving coal mining method using comprehensive mechanized equipment

Longwall roof-caving coal mining method using comprehensive mechanized equipment is a mining coal method invented by China to mine extra-thick coal seam. Applying this method has always been controversial for its lower coal mining rate. It's hard to drain harmful gas gathered above the mined-out area off and enormous ground subsidence induced by mining full-thickness one time .

(5) The short wall comprehensive mechanized coal mining method

The short wall comprehensive mechanized coal mining method is one of application methods for mining under water-containing laying. It mainly includes chamber mining method, room and pillar mining method, gateway and pillar mining method, and shortwall coal mining method in certain conditions. This method bring small mining scale and have little influence on the stability of aquifuge 
but the mining efficiency is relatively low. The lower mining rate results in wasting mass coal resources, and there are some problems in production system and its security, so this method has been listed as uncommon mining method and is no longer applicable in recent years .

(6) Pillar mining coal method

Pillar mining coal method is a widely used mining method where mining coal needs protecting facility on the ground. This method divides mining coal area into some standard band zones, one of which is mined and one is left untouched in order to control the subsidence in overburden of ground to protect buildings, roads, and water resources. This method can always apply where mining activity is close to water body and bring big safety threat. Because using this method results in lower mining rate, more roadway to driving, and lower efficiency in mining face, it's not suitable for application in widely range area .

(7) Filling working face after mining method

Filling workface after mining method is to use solid waste like gangue and coal ash, mix them in certain proportion, and fill out the mined coal in the form of volume. Applying this method can greatly reduce the overburden fissure height, but great amount of sand or soil are needed for the mass filling, so it only applied in the key mining area, and is not suitable for mass adopting. Widely using this method will increase the cost and bring negative influence on environment.

\section{The research and application of mining methods}

In general, there are three measures to implement safety mining under water body, which are the mining method reserved waterproof coal pillar in advanced, the method advance white-out water, special mining method. The purpose of these techniques are to ensure the safety production under mine. Advanced reserve water-proof pillar is the main water protection mining method in the burned rock area in north of Shaanxi province. Draining water in advance is widely used method in Shendong mine area. But this method destroys the underground water in and damages the ecological environment. Nowadays this method is not suitable for eco-fragile region mining coal with the mining scale increase. Therefore, it is very important to study mining methods to implement mining under water-containing layer.

Since 2006, FAN Limin has proposed a project that use different mining method in different situation and area, aiming at the problem of mining under water-containing layer in north of Shaanxi province. For the shallow buried coal in north of Yushen mine area, the water-preserved-mining technique scheme changes from chamber pillar mining method to band mining method to achieve the goal of preserving water mining ${ }^{[27,30]}$. LIU Yang used the software RFPA-2D to simulate the mechanics processes of wall rock destruction in various ratio of extraction to reservation with the method of band mining. He proposed the technique parameters of band mining, which formed a narrow band mining technique under water-containing layer, promoted technology level of small and medium-sized coal mines with rich water in Yushen coal mine areas, and laid a theoretical foundation for recovery rate and preserving water mining. It had a successful application in Yupujie coal mine ${ }^{[31]}$. ZHANG Shaochun also did experiment of the simulation and put forward the intermittent mining method for preserving water. He held that band mining method, or room pillar mining method must be used or not mine the coal ream at all when a roof layer is less than 30 meter $^{[32]}$.

HUANG Gingxiang studied the character of aquifuge and mining water-resisting property, and the longwall mining method under water-containing layer and carried on engineering practice. MA Liqiang took the Bulianta coal mine in Shendong mining area as an example to validate that longwall preserving water mining technique with the rapidly moving forward working face can achieve success where there are appropriate geological conditions. He put forward a reference for improving the recovery rate of coal resources and ecological environment construction in west shallow buried coal mining area. WU Ya'an simulated the overburden stability in three mining method which are limited height mining method, Longwall pillar mining method and band mining method that is used in mining twelve and remaining eight. He confirmed the mining scheme of Daliangwan coal mine by analyzing the simulation of three mining method and provided mining coal research with a reference. Based on the special geological condition in loess gully region, FAN Limin presented longwall mining method 
and it could increase coal recovery rate and significantly decrease the mining area and reduce mining-disturbed damage when mining the same coal. The eighty-four coal mine in Fugu county applied the longwall mining method, approaching the goal of reducing mining-disturbed damage and increasing recovery ratio .

Shaanxi coalfield geology bureau propose a filling mining method which means filling the goaf while mining is being done to decrease the roof destruction, aiming at preserving water.

\section{The development trend in this research field}

The preserving water mining is an indispensable part of constructing green mining area. The technique study and engineering practice on preserving water mining are vital tasks to build the Chinese large scale coal base. The following three aspects should be in further studies to better carry out preserving water mining to protect the environment and to achieve sustainable development. Firstly, space combination characteristics of different overlaying structure should be further studied to provide basic conditions for reasonably sectional mining under the water-containing layer and chose the suitable mining technology for roof and floor protection. Secondly, pay attention to basic geological exploration and research and study the combination forms, existing property, physical and mechanical properties, hydraulic properties about water, coal and rock in three-dimensional space and study mining strata deformation and failure rules combining comprehensive survey of water resources, coal resources and mining conditions. Thirdly, study technical parameters and approaches in special mining methods. Fourthly, increase multidisciplinary intersection study, absorb the latest research results in related disciplines, and promote research theories to be perfect.

\section{Acknowledgements}

This work was financially supported by the National Natural Science Foundation of China (Grant No. 41272388).

\section{References}

[1] CHEN Mingzhi mine water resource protect development and utilization in China [J].Coal Mine Environmental Protection, 1997, 11(1): 46 - 47.

[2] WANG Yue. The research on technical scheme of coal mining under water-containing conditions in Yushuwan coal mine [D]. Xi'an University of Science and Technology,2012

[3] QIAN Ming-gao ,XU Jia-lin ,MIAO Xie-xing.Green technique of coal mining[J].Journal of China University of Mining \& Technology,2003, 32(4): 343 - 348.

[4] YANG Ben-sheng ,ZHANG Lei.The rapid discriminant key strata location and predict weighting[J].Coal Engineering, 2013, 7: 79 - 81.

[5] XU Jia-lin ,WANG Xiao-zhen, LIU Wen-tao . Effects of primary key stratum location on height of water flowing fracture zone[J].Chinese Journal of Rock Mechanics and Engineering, 2009, 28(2): $380-385$.

[6]XU Jia-lin ,ZHU Wei-bing, WANG Xiao-zhen .New method to predict the height of fractured water-conducting zone by location of key strata[J],Journal of China Coal Society , 2012, 37(5): 762 769.

[7] WANG Xiao-zhen ,XU Jia-lin ,ZHU Wei-bing .Influence of primary key stratum structure stability on evolution of water flowing fracture [J].Journal of China Coal Society, 2012, 37(4): 606 612.

[8] HOU Shi-jie Analysis of combinatorial key strata stability in shallow coal seam with thick loose bed[J],Journal of China Coal Society, 2000, 25(2): 127 - 131.

[9] CHEN Kai ,YAN Gui-feng, WEN Jiang application of trend surface analysis on predicting height of water-flowing fractured zone[J]. China Coal, 2013, (2): 52 - 54. 
[10]SHI Qing-long, XIN Heng-qi .calculating the height of water flowing fracture zone in deep mining [J].Journal of China University of Mining \& Technology,2012, 41(1): 37 - 41.

[11] State Bureau of coal industry. Building the railway under the water and coal pillar design and coal mining regulations[S]. Beijing Coal Industry Press, 2000. (in Chinese))

[12]Ministry of Coal Industry .Mine hydrogeological regulations[M]. 1984, China coal industry publishing house

[13] LIU Chuan-wu, ZHANG Ming, ZHAO Wu-sheng . Using acoustic testing technique to confirm the broken floor depth after minig[J].Coal science \& technology magazine, 2004, (4): 4 - 5.

[14] BAO Jing-long, YANG Cong-wen, WANG Ji-an .Application of Double-block Leak Hunting in Drill in Detecting Height of Fracture Zone at Coal Face [J] Coal Technology, 2011, 30(4): 77 - 78.

[15] WAGN Hua , CHENG Hua , LIU Sheng-dong . Research on Timely Prospecting Technology of Water Flowing Fracture Zone by Parallel Electrical Resistivity Method[J]. Safety in Coal Mines,2007,38(7):1-5.

[16] WANG Qi-qing ,LI Wen-ping ,LI Tao .Division types of geological conditions at mining with water protection in ecological fragile area of northern Shaanxi[J]. Journal of Engineering Geology, 2014, 22(3): 028.

[17] MA Qing-yun ,TANG Jian-quan.Study on the procedure of overlying strata movement and failure [J]. Journal of Mining \& Safety Engineering,2000,(2): 32 - 33.

[18] HUANG Qing-xiang, ZHANG Wen-zhong, HOU Zhi-cheng .Study of simulation materials of aquifuge for solid-liquid coupling[J].Chinese Journal of Rock Mechanics and Engineering, 2010, 29(): 2813 - 2817

[19] FAN Gang-wei , ZHANG Dong-sheng ,MA Li-qiang . Overburden movement and fracture distribution induced by longwall mining of the shallow coal seam in the Shendong coal field[J]. Journal of China University of Mining \& Technology, 2011, 40(2): 196 - 201.

[20] WANG Xiao-zhen, XU Jia-lin, ZHU Wei-bing. Study on the influence of the characteristic of unconsolidated confined aquifer on its property of load transfer [J].Journal of Mining \& Safety Engineering, 2014, 31(4): 499 - 505.

[21] XU Jia-lin ,ZHU Wei-bing,WANG Xiao-zhen . Study on water-inrush mechanism and prevention during coal mining under unconsolidated conined aquifer [J]. Journal of Mining \& Safety Engineering, 2011, 28(3): 333 - 339.

[22] HUANG Qing-chun.Impermeability of overburden rock in shallow buried coal seam and classification of water conservation mining [J].Chinese Journal of Rock Mechanics and Engineering, 2010, 29(A02): 3622 - 3627.

[23]Charlie C.Li. Disturbance of mining operations to a deep underground workshop[J]. Tunneling and Underground Space Technology, 2006, 21: 1 - 8.

[24] FAN Juan, ZHANG Wen-zhong .Analysis on mechanics characteristics of overburden stress shell structure in Yushuwan coal mine[J]. Ground Water, 2013, 35(4): 169 - 172.

[25]GUAN Kai, DONG Tao, JIA Jin-long .Coupling Effect Analysis of the Shallow Seam of Topsoil and Key Stratum to Surface Subsidence Based on the UDEC[J].Safety in Coal Mines2012, 43(3): 161 $-163$.

[26] ZHANG Rong-liang, MA Feng-hai,YANG Fan.Analysis of surface deformation of a rock mass with a inclined coal seam using ANSYS[J] The Chinese Journal of Geological Hazard and Control,2006, 17(1): 91 - 94.

[28] WANG Yue ,XIA Yu-cheng, DU Rong-jun. Discussion on maximum mining height of coal mining under water-containing condition in one mine field of northern Shaanxi province[J].Journal of Mining \& Safety Engineering , 2014, 31(4): 558 - 563.

[29] ZHAO De-shen ,XU Meng-lin.Three-dimensional numerical simulationin of damage of overlying strata in mining of thick coal seam[J]. Journal of Guangxi University(Natural Science Edition), 2013, 38(1): 235 - 239. 
[31] LIU Yang, SHI Wu-ping,ZHANG Zhuang-lu .Technique Parameters Analysis of Strip Mining without Destroying Water Resource in Low- burying Coal Seam[J].Coal Mining Technology, 2007, 11(6): $6-10$

[32]ZHANG Sao-chun ,ZHANG Jie , XIAO Yong-fu . Expermiental research on reasonable advance distance for water protection mining[J].Shaanxi Coal,2005, 24(1): 17 - 19. 